\title{
DIAGNOSTIC OF MELANOMAS VIA IMAGE PROCESSING
}

\author{
O. Hochmuth, Beate Meffert
}

Department of Electrical Engineering, Humboldt University Berlin

\section{ABSTRACT:}

Non-contact measuring of skin temperatu$r e$ is used in dermatology as diagnostic method for malignant melanomas and other skin deseases $[1,2,3]$. The method helps to examine pathological processes under the skin and is useful for a decision on minimal-surgical or non-surgical therapy. In a first step of investigation it is necessary to get knowledge about the required resolution in temperature and space.

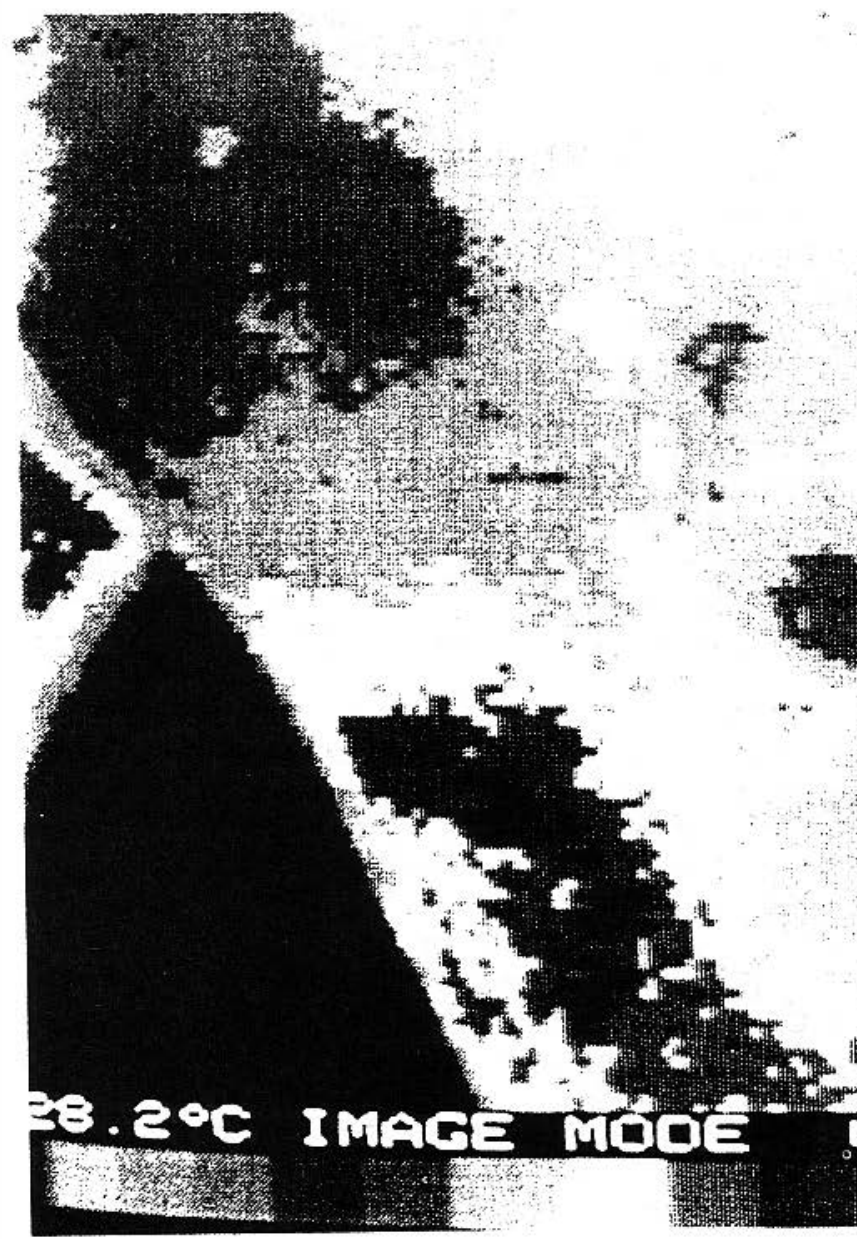

\section{METHOD:}

After a visual inspection of the skin regions of interest the temperature map were measured by a $2 D$ infrared thermography equipment INFRAMETRICS 760 . The infrared images were further processed by a computer (see Fig. 1).

Thermography systems with radiation sensors fulfil in addition to the requirement of non-contact measurement the conditions of the spectral sensitivity in the range

Fig. 1: Thermography image of a right thigh with a pathological process in the centre 
of 8 to $12 \mu \mathrm{m}$ and of the resolution of $0,1^{\circ} \mathrm{C}$. The measurement gives about 200 samples per line, dependent of the size of the region.

The procedure for determination of the required local resolution has to calculate spatial frequencies in the infrared images. For this, a spectral transform of the measured temperature curve in one dimension of space is sufficient. A typical behaviour of skin temperature with an increase in the centre of the melanoma is shown in Fig. 2.

The approximation is possible by different procedures, e. g. by a harmonic analysis via the Fast Fourier Transform [4,5].

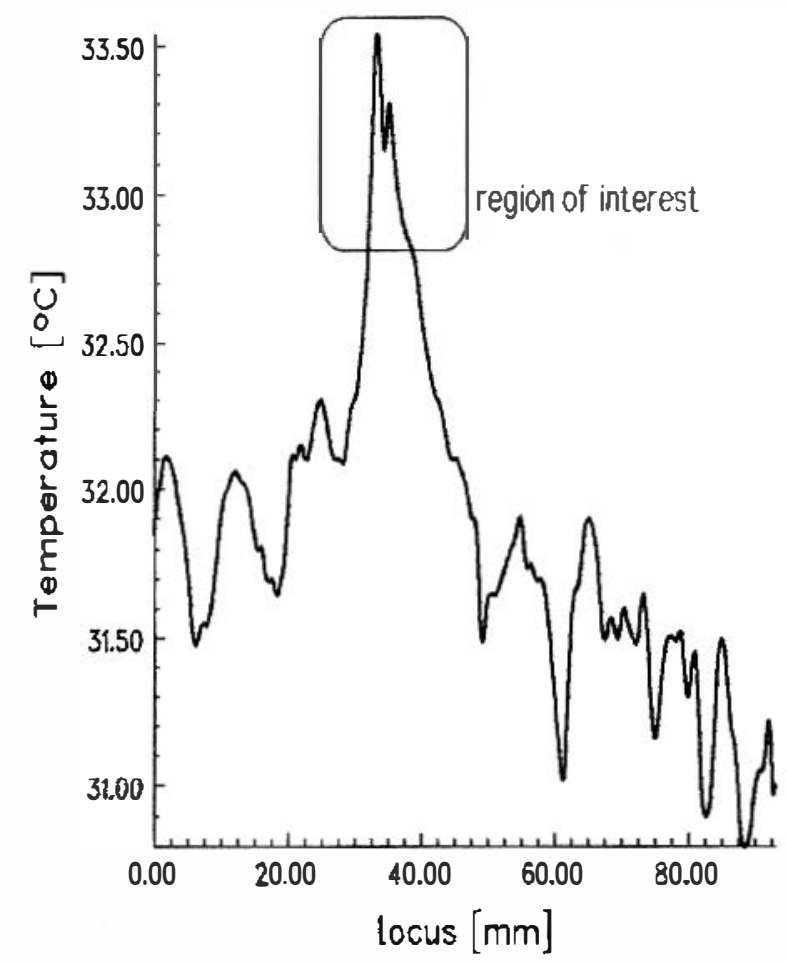

Fig. 2: Temperature curve versus locus

\section{RESULTS}

First inverstigations showed that the span is $3^{\circ} \mathrm{C}$ and the maximum important spatial frequency is $0.632 \mathrm{~cm}^{-1}$ if the resolution of temperature is $0.1^{\circ} \mathrm{C}$. Therefore, the required spatial resolution should be at least 6 samples per centimetre (see Fig. 3).
Based on these knowledge it is possible to design a low cost 1D image processing equipment for further investigations.

\section{REFERENCES}

[1] H. Meffert, B. Meffert, N. Sönnichsen: Zur Messung der Hauttemperatur mit dem Infrarot-Strahlungsmeßgerät nach Kortum. Dermatol. Monatsschrift, vol. 155, p. 802, 1969

[2] E. Schwamm: Tumordiagnostik durch Hauttemperatur-Messung. Physikalische Medizin und Rehabilitation, vol. 15, pp. 253-255, 1974

[3] C.M. Balch et al: Tumor thickness as a guide to surgical management of clinical stage I melanoma patients. Cancer, vol. 43, p. 883,1979

[4] P. Haberäcker: Digitale Bildverarbeitung. München: Carl-Hanser-Verlag 1991

[5] H. Götz: Einführung in die digitale Signalverarbeitung. Stuttgart: TeubnerVerlag 1990

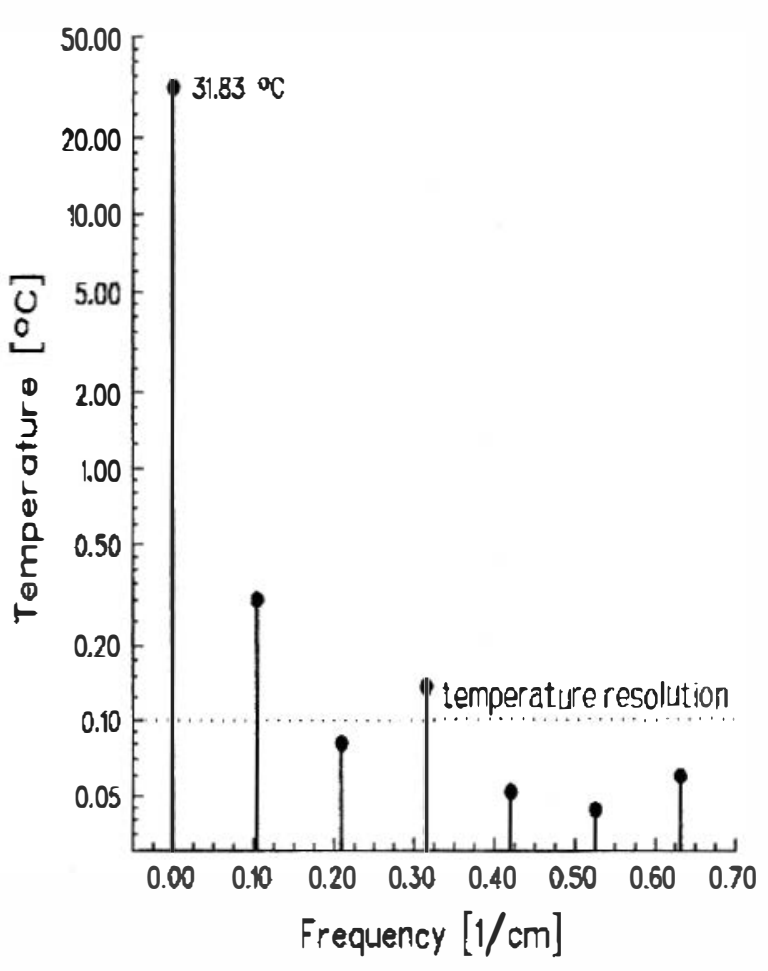

Fig. 3: Typical temperature spectra

\section{Biomedizinische Technik Band 38 • Ergänzungsband • 1993}

